\title{
A value-based philosophy debate on academic midwifery education in Europe
}

\author{
Joeri Vermeulen ${ }^{1,2}$, Victoria G. Vivilaki ${ }^{3}$
}

\section{Background}

Worldwide midwifery educators are passionate about educating the next generation of midwives and prepare them to contribute to public health and the midwifery profession. A redesign and transformation of midwifery education may be needed, focusing on the longterm impact on mothers, families and communities. To meet these challenges, midwifery students are expected to acquire competences in all fields of midwifery according to both national and European legislation and the International Confederation of Midwives (ICM) Global Standards for midwifery education ${ }^{1}$.

The landscape of Higher Education initiated a transparent and easily comparable system of academic degrees in Europe. In 1999, an educational system in three cycles was established (Bachelor's, Master's and Doctorate level), by the so called Bologna process ${ }^{2}$. In recent years, midwifery educational reforms shifted from vocational training to academic education in Europe, which enhanced opportunities for mobility, employability and research. A recent study (2019) confirmed that, in most European countries, midwifery education took place at university (19 at Bachelor's and in seven at Master's level). Only four countries still offered vocational diploma level programs ${ }^{3}$. Nevertheless, midwives from different countries have uneven levels of proficiency, scope of practice, and education. While variation exists, some countries face challenges operating in a European context where midwifery is regulated, measured and documented in a similar way enabling comparison and impact ${ }^{4}$.

\section{Advantages and implications of academic educational pathways to midwifery}

Academic degree programs are of great value to individuals, and offer easier access to career pathways. According to a Swedish study, exploring the effects of academization of midwifery education ${ }^{2}$, such a system leads to an additional academic degree at postgraduate level. The majority of European researching midwives, implemented and coordinated research projects and demonstrated action research only after the implementation of the Bologna process 5 . By consequence, the underpinning philosophy of evidence for midwifery practice was advanced. Academization of midwifery education strengthened not only the profession but also the evidence-based knowledge and skills in theory and practice ${ }^{6}$. Stronger focus on midwifery research and evidence-based practice can contribute to midwifery students' readiness for clinical practice. Additionally, advanced midwifery education has the potential to contribute to a higher level of critical thinking skills, which are beneficial in the provision of quality maternity care ${ }^{7}$.

\section{Underpinning philosophy for academic midwifery education}

Powerful academic competences for the midwifery educators ${ }^{6}$

In most European countries opportunities for Master's and PhD degrees in midwifery, or related disciplines, are available ${ }^{3}$. However, opportunities for collaboration between undergraduate and postgraduate level need further exploration. A symbiosis of these education levels may facilitate postgraduate academic education and professional development of educators, while meeting the need to upgrade their competence level to an academic one.

Midwifery educators are undoubtedly the critical factor in guaranteeing the quality of midwifery education, therefore their competence level needs careful consideration. WHO's midwifery educator core competences $(2014)^{8}$ describes four out of the eight competence domains on an advanced level such as: 'maintaining current knowledge

\section{AFFILIATION}

1 Department Health Care, Brussels Centre for Healthcare Innovation, Erasmus Brussels University of Applied Sciences and Arts, Brussels, Belgium 2 Faculty of Medicine and Pharmacy, Department of Public Health, Biostatistics and Medical Informatics Research group, Vrije Universiteit Brussel, Brussels, Belgium

3 Department of Midwifery, School of Health and Care Sciences, University of West Attica, Athens, Greece

\section{GORRESPONDENGE TO}

Joeri Vermeulen. Department Health Care, Brussels Centre for Healthcare Innovation, Erasmus Brussels University of Applied Sciences and Arts, Laarbeeklaan 121, 1090 Brussels, Belgium. E-mail: joeri.vermeulen@ehb. be ORCID ID: http://orcid. org/0000-0002-9568-3208

\section{KEYWORDS}

midwifery education, midwifery students, academic degree, competence, educational standards

$\nabla$

Received: 29 October 2021 Accepted: 2 November 2021 
\& skills in midwifery theory and practice based on best evidence available', 'responsibility for conducting regular monitoring, evaluation and assessment of programs and students', 'effective communicators and functioning as advocates, change agents \& leaders', and 'promoting the use of research and use it to inform midwifery education and practice'. Besides these academic challenges, it is highly recommended to enrich the education team with stakeholders in maternity care, women included, whose visions will be added value in academic midwifery education.

\section{Leading international educational standards}

Essential and academic competences need to be in line with ICM Global Standards for midwifery education. While most European midwifery education programs have implemented the regulatory requirements of the European Directives ${ }^{9}$ in their national regulation on midwifery education, it may be assumed that midwifery students achieve the requested competences during their education. Above all, readiness for practice should be guaranteed for all graduates. A study evaluating views about Swedish academic midwifery education concluded that few respondents were dissatisfied with how midwives were prepared for practice. Although, the majority of responding midwives and obstetricians would have liked more attention on intrapartum care, medical complications, and emergency situations in the education program. Educational managers need to keep in mind today's complexity of practice ${ }^{10}$. The involvement of stakeholders in maternity care such as midwives from all domains, other maternity health professionals, and women, is again vital. Additionally, the ICM curriculum mapping tool may be helpful to analyze and optimize midwifery education programs $^{11}$

\section{Academic degree at Bachelor's or Master's level}

Academic focus on research theory and methods, and promoting critical thinking skills, aims to prepare new midwives to be better equipped to meet the demands of evidence-based maternity care. The question is whether the balance between these two challenges for midwifery education has been optimized, e.g. to be research based and to provide competent midwives to face the challenges of today's maternity care. A comprehensive educational model that meets both challenges is needed to assist students to acquire the essential and academic competences in all fields of midwifery. An integrative midwifery educational model was recently developed at the Erasmus Brussels University of Applied Sciences and Arts and the Vrije Universiteit Brussel (VUB), Brussels, Belgium, to meet these challenges. Perinatal simulation training and case-based clinical reasoning are key components of the integrative educational model ${ }^{12}$. The innovation of the concept lies in a progression of complexity, the mixed teaching strategies and a structural embedment of the model in the entire midwifery education curriculum. Our approach optimizes student midwives to acquire all competences for midwifery practice and to develop confidence. As such, it improves student midwives' readiness for practice.
An important challenge for midwifery education in the future is the involvement of medical students and trainees in obstetrics to promote competences that are indispensable in multidisciplinary practice. Interprofessional education has been acknowledged as a mechanism to improve the overall quality of students' performance in healthcare ${ }^{13}$. In interprofessional education, students from different disciplines learn from each other in a safe learning environment ${ }^{14}$. Although there are barriers to interprofessional education, we advocate to extend interprofessional education to different topics, e.g. basic and advanced life support, biomedical ethical cases, and a structural embedment in midwifery education programs.

\section{Conclusion}

There is a huge opportunity for midwifery education to add value in all domains of public health in line with national and European legislation and ICM global standards. Academic midwifery qualifications will positively affect maternal and neonatal outcomes - the future of the communities and will stimulate further professionalization of midwifery. Nonetheless, midwifery education should be associated with the actual rather than the perceived value of degree requirements so that student midwives are ready to face the challenges of today's maternity care.

The European Community demands a paradigm shift in Higher Education, by further investment in academic education and continuous professional development of educators. Investing in clinical and research training would lead to a new era of potentialities that may help to develop competence and promote midwifery leadership. Even though an academic degree is beneficial to students, women's health and the midwifery profession, the narrative can be optimized by the involvement of stakeholders and collaborative learning methods as measures of competence and employability in Europe.

\section{REFERENGES}

1. International Confederation of Midwives. ICM GLOBAL STANDARDS FOR MIDWIFERY EDUCATION (REVISED 2021). International Confederation of Midwives; 2021. Accessed October 29, 2021. https://www. internationalmidwives.org/assets/files/generalfiles/2021/09/global-standards-for-midwiferyeducation_2021_en.pdf

2. Hermansson E, Mårtensson LB. The evolution of midwifery education at the master's level: a study of Swedish midwifery education programmes after the implementation of the Bologna process. Nurse Educ Today. 2013;33(8):866-872. doi:10.1016/j.nedt.2012.09.015

3. Vermeulen J, Luyben A, O'Connell R, Gillen P, Escuriet $\mathrm{R}$, Fleming $\mathrm{V}$. Failure or progress?: The current state of the professionalisation of midwifery in Europe. Eur $J$ Midwifery. 2019;3(22):1-9. doi:10.18332/ejm/115038

4. Fleming V, Pehlke-Milde Hebamme J, Davies S, Zaksek $\mathrm{T}$. Developing and validating scenarios to compare midwives' knowledge and skills with the International Confederation of Midwives' essential competencies in 
four European countries. Midwifery. 2011;27(6):854860. doi:10.1016/j.midw.2010.09.003

5. Luyben AG, Wijnen HA, Oblasser C, Perrenoud P, Gross $\mathrm{MM}$. The current state of midwifery and development of midwifery research in four European countries. Midwifery. 2013;29(5):417-424. doi:10.1016/j.midw.2012.10.008

6. Bogren M, Ndela B, Toko C, Berg M. Midwifery education, regulation and association in the Democratic Republic of Congo (DRC) - current state and challenges. Glob Health Action. 2020;13(1):1717409. doi:10.1080/16549716.2020.1717409

7. Fullerton JT, Johnson PG, Thompson JB, Vivio D. Quality considerations in midwifery pre-service education: exemplars from Africa. Midwifery. 2011;27(3):308-315. doi:10.1016/j.midw.2010.10.011

8. World Health Organization. Midwifery educator core competencies: building capacities of midwifery educators. World Health Organization; 2014. Accessed October 29, 2021. https://www.who.int/hrh/nursing_ midwifery/14116_Midwifery_educator_web.pdf

9. Vermeulen J, Luyben A, Jokinen M, Matintupa E, O'Connell R, Bick D. Establishing a Europe-wide foundation for high quality midwifery education: The role of the European Midwives Association (EMA). Midwifery. 2018;64:128-131. doi:10.1016/j.midw.2018.06.009

10. Schytt E, Waldenström U. How well does midwifery education prepare for clinical practice? Exploring the views of Swedish students, midwives and obstetricians. Midwifery. 2013;29(2):102-109. doi:10.1016/j.midw.2011.11.012

11. International Confederation of Midwives. CURRICULUM MAPPING TOOL, CONCORDANCE OF MIDWIFERY CURRICULUM WITH ICM: Essential Competencies for Basic Midwifery Practice. International Confederation of Midwives; 2013. Updated May, 2013. Accessed October 29, 2021. https://web. archive.org/web/20170713142020/http:// www.internationalmidwives.org/assets/uploads/ documents/CoreDocuments/ICM\%20Curriculum\%20 concordance\%20map\%20-revised\%202013.pdf

12. Vermeulen J, Vandelannoote I, Fobelets M, De Clercq G, Beeckman K. An integrative educational model aiming to improve student midwives' readiness for practice in Brussels, Belgium. Eur J Obstet Gynecol Reprod Biol. 2019;234:e40. doi:10.1016/j.ejogrb.2018.08.242.

13. Buring SM, Bhushan A, Broeseker A, et al. Interprofessional education: definitions, student competencies, and guidelines for implementation. Am J Pharm Educ. 2009;73(4):59. doi: 10.5688/aj730459

14. Darlow B, Coleman K, McKinlay E, et al. The positive impact of interprofessional education: a controlled trial to evaluate a programme for health professional students. BMC Med Educ. 2015;15:98. doi:10.1186/s12909-015-0385-3

\section{CONFLICTS OF INTEREST}

The authors have each completed and submitted an ICMJE for Disclosure of Potential Conflicts of Interest. The authors declare that they have no competing interests, financial or otherwise, related to the current work. Victoria Vivilaki reports that she is the Editor-in-Chief of the EJM journal and Joeri Vermeulen reports that he is the Associate Editor of the EJM Journal.

\section{FUNDING}

There was no source of funding for this research.

\section{ETHICAL APPROVAL AND INFORMED CONSENT}

Ethical approval and informed consent were not required for this study.

\section{DATA AVAILABILITY}

Data sharing is not applicable to this article as no new data were created.

\section{PROVENANGE AND PEER REVIEW}

Not commissioned; internally peer reviewed. 